\title{
Autologous grafting of non manupulated freshly isolated - adipose tissue derived stromal vascular fraction in single surgical sitting for treatment of knee osteoarthritis
}

\author{
Vinay Tantuway ${ }^{1}$, Pawan Bhambani ${ }^{2}$, Ashok Nagla ${ }^{1}$, Piyush Mantry ${ }^{3}$, Raj Sharma ${ }^{3}$, \\ Pankaj Mehto $^{3}$, Swati Bansal ${ }^{4}$
}

\author{
${ }^{1}$ Department of Orthopedics, ${ }^{2}$ Department of Pathology, Index Medical College Hospital \& Research Centre, Index \\ City, Nemawar Road, NH-59A, Indore, M.P, India \\ ${ }^{3}$ Sahaj Regenerative Cell Therapeutics LLP, 13/2, South Tukoganj, Indore, M.P., India \\ ${ }^{4}$ Arthros Clinic, Sahaj Hospital, 15/2 South Tukoganj, Indore, M.P., India
}

Received: 10 December 2016

Revised: 23 December 2016

Accepted: 26 December 2016

\section{*Correspondence:}

Dr. Vinay Tantuway,

E-mail: drvtantuway@gmail.com

Copyright: ( ) the author(s), publisher and licensee Medip Academy. This is an open-access article distributed under the terms of the Creative Commons Attribution Non-Commercial License, which permits unrestricted non-commercial use, distribution, and reproduction in any medium, provided the original work is properly cited.

\begin{abstract}
Background: Osteoarthritis (OA) is one of the major cause of morbidity, having a substantial influence on health quality of life, imposing enormous burden of cost on the health care system. It is a chronic degenerative disorder that is characterised by articular cartilage degeneration. It can be caused by aging, heredity and injury from trauma or disease. Primary symptoms of OA include joint pain, stiffness and limitation of movement. Disease progression is usually slow but can ultimately lead to joint failure with pain and disability. Stromal vascular fraction (SVF) derived from adipose tissue is a rich source of pre adipocytes, mesenchymal cells (MSC), endothelial progenitor cell, T cells, $\mathrm{B}$ cells, mast cells as well as adipose tissue macrophages. It can be easily obtained from loose connective tissue that is associated with adipose tissue by lipoaspiration under local anaesthesia. SVF is isolated without using any enzymes or chemicals and its autologous grafting is done in a single surgical sitting. Here, we evaluated safety and clinical efficacy of freshly isolated Autologous SVF cells in patients with grade 2-4 degenerative osteoarthritis (OA). .

Methods: A total of 116 joints mainly knee OA were treated with autologous grafting of SVF done in a single surgical sitting. A total of 116 joints studied out of which 80 joints were followed up for 12 months, 88 joints followed for 9 months, 110 joints followed for 6 months and finally all 116 joints were followed for minimum 1 month for safety and efficacy.

Results: Modified KOOS clinical score was used to evaluate clinical effect and was based on pain, non-steroid analgesic usage, limping, extent of joint movement, and stiffness evaluation before and at pre-operative, 1 Month post-op, 6 months post-op and 12 Months post-op after grafting. No side effects, systemic infection or cancer was associated with Autologous grafting of SVF. There was a significant improvement from pre-op to post op in all the followed patients. Average KOOS score improved from pre-operative 46.4 to post-operative 12 months average 77.9 i.e. very significant improvement in all grades. All sub-scale parameter for pain, symptoms, activity of living and quality of life showed significant improvement. Higher grade of OA were associated with comparatively slower healing.

Conclusions: Autologous grafting of SVF in single surgical sitting is a novel and promising treatment approach for patients with degenerative OA. This treatment method was found to be minimal invasive, safe and cost-effective treatment modality for osteoarthritis.
\end{abstract}

Keywords: Osteoarthritis, Musculoskeletal disease, Stromal vascular fraction, Fraction of adipose tissue, Autologous grafting, Knee injury and osteoarthitis outcome score 


\section{INTRODUCTION}

The burden of musculoskeletal disease (MSD) is global and looking at the gravity of the situation and due to its increasing prevalence associated with large personal and societal costs. MSD is recognised as a major health problem. They are the most collective cause of severe long term pain and physical disability, and they affect hundreds of millions of people around the world. ${ }^{1}$ Osteoarthritis (OA) is a common chronic, progressive musculoskeletal disorder characterized by gradual loss of articular cartilage. This disease most commonly affects the elderly and middle-aged, while it may begin earlier as a consequence of injury or overuse. Further it is painful in weight bearing joints such as the knee and hip.

Ageing, heredity and injury from trauma or disease are its major causes. Osteoarthritis is the most widespread form of arthritis in the world. The prevalence of osteoarthritis increases indefinitely with age, because the condition irreversible. Women are more affected than man among those aged $<45$ years, whereas women are affected more frequently among those aged $>55$ years. ${ }^{2}$ Worldwide estimates are that $9.6 \%$ of men and $18.0 \%$ of women aged $\geq 60$ years have symptomatic osteoarthritis. ${ }^{3}$ Osteoarthritis is already one of the ten most disabling diseases in developed countries. $80 \%$ of those with osteoarthritis will restricted in movement, and $25 \%$ cannot perform their major daily activities of life. ${ }^{4}$ Increase in the life expectancy and ageing populations are expected to make osteoarthritis the fourth leading cause of disability by the year $2020 .^{1}$

The CDC combined data from the National Health Interview Survey (NHIS) years 2010-2012 sample adult core components to estimate average annual arthritis occurrence in the civilian, non-institutionalized US adult population aged 18 years or older. Overall, $22.7 \%$ (52.5 million) of adults reported doctor-diagnosed arthritis, with significantly higher age-adjusted prevalence in women $(23.9 \%)$ than in men (18.6\%). Arthritis prevalence increased with age. $^{5}$

With the aging of the US population, the prevalence of doctor-diagnosed arthritis is projected to increase in the coming decades. By the year 2040, an estimated 78 million (26\% of the projected total adult population) adults aged 18 years and older will have diagnosed arthritis, compared with the 52.5 million adults in 20102012. Two-thirds of those with arthritis will be women. Also by 2040, an estimated 35 million adults will report arthritis-attributable activity limitations. These estimates may be conservative, as they do not account for the current trends in obesity, which may contribute to future cases of osteoarthritis. This figure is more alarming in India rise with a study saying we have over 180 million patients in India and this figure will increase in future. ${ }^{5}$
X-rays are still the main diagnostic tool however arthroscopy, ultrasound, MRI, CT scan etc. are used specially for experimental studies and not recommended for routine clinical use. ${ }^{6}$ The goal of treatment in osteoarthritis is to reduce joint pain while improving and maintaining joint function. ${ }^{7}$ The cartilage is a unique avascular, aneural tissue that has limited capacity of selfrepair once damaged. OA of weight-bearing joints is associated with chronic devastating pain, stiffness, decreasing range of motion and joint deformity, being one of the leading causes of decreased quality of life and work limitations. Despite ongoing research, treatments to manage the disease remain symptomatic. Treatment generally involves a combination of lifestyle modifications, analgesics, NSAIDs and joint injections with steroids or hyaluronic acid (lubricant). If pain becomes debilitating, joint replacement surgery may be used to improve the quality of life, e.g. fractional joint resurfacing, and total joint replacement (hip and knee). Total joint arthroplasty (TJA) is the mainstay of treatment for end-stage OA of the hip or knee. Unfortunately, TJA is relatively frequently associated with serious and lifethreatening complications including increased risk of infection, thromboembolism, myocardial infarction, stroke, cancer, increased risk of death at 30 and 90 days after surgery, and the life-span of the prosthesis is limited. ${ }^{8-11}$ Also long term use of analgesics may be associated with radiographic progression of knee OA. ${ }^{12}$

The mononuclear fraction of adipose tissue, referred to as the stromal vascular fraction (SVF) was originally described as a mitotically active source of adipocyte precursors by Hollenberg et al. in $1968 .{ }^{13}$ Recently, it was shown that stromal vascular fraction hold a great promise for their healing potential for Cartilage damage. ${ }^{14}$ Preclinical animal studies that utilize MSCs demonstrated safety and efficacy in treatment of OA, cartilage defects or other orthopedic conditions. ${ }^{15-18}$ The grafting of Autologous SVF derived from adipose tissue as a treatment option has been rapidly gaining momentum globally. There are now a significant number of clinical trials listed on clinicaltrials.gov and ongoing studies that support many variations of these therapies.

In humans, the large collection of culture-expanded bone marrow-derived MSCs were used for treatment of 339 patients with $\mathrm{OA}$ and more than $75 \%$ improvement was reported in $41.4 \%$ and more than $50 \%$ improvement was reported in $63.2 \%$ of patients. No severe side effects and no neoplastic complications were detected at any cell reimplantation site in a mean follow-up 435 days. ${ }^{19}$

A total of 1856 joints mainly knee and hip joints were treated with a single dose of SVF cells and a follow up after treatment was done at 3,6 and 12 months and found that $75 \%$ score improvement was found in $63 \%$ of the patients and at least $50 \%$ score improvement was noted in $91 \%$ of the patients after 12 months of after the therapy. ${ }^{20}$ 
Adipose derived stromal vascular fraction (SVF), containing large number of cells. Adipose tissue-derived MSCs are more genetically stable in a long term culture, display a lower senescence ratio and higher proliferative capacity. ${ }^{18}$ Bone marrow MSCs constitute only about $0.001 \%-0.01 \%$ of all nucleated cells in bone marrow, whereas the amount of adipose tissue-derived MSCs is approximately 1000-fold greater when isolated from equivalent volume of tissue. ${ }^{18,21,22}$ Adipose tissue can be easily obtained by standard lipoaspiration under local anaesthesia and isolated stromal vascular fraction (SVF) cells contain 1-4\% MSCs as well as other cell types involved in tissue regeneration such as vascular endothelial cells, pericytes, fibroblasts, macrophages and regulatory T lymphocytes. ${ }^{18,23-25}$ SVF cells demonstrated anti-inflammatory and immunomodulatory effects and MSCs have the capacity to differentiate into connective tissue cells including cartilage, tendon and ligament. ${ }^{18,26}$.

\section{METHODS}

A prospective experimental research design is adopted in this study 145 joint of patients attending Ortho OPD at Index Medical College Hospital \& Research Centre, Indore and Arthros Clinic, Sahaj Hospital, Indore were included in the study who had osteoarthritis as well as rheumatoid arthritis. The study was carried out from May 2015 to August 2016. Institutional Ethics Committee had been sought before enrolment of study participants. Informed written was taken from each individual study participants who undergone SAF therapy. All the study patients who fulfilled inclusion criteria had underwent SVF surgery. Out of which 82 joints of patients were followed for their improvement in their scores of (pain, symptoms, activity of living, quality of life) in mentioned schedule - Pre-SVF; after 1 week; 1, 3, 6, 9 and 12 month of surgery and 63 joints are being studied of more than 3 months. Further study will be done with more number of patients with longer follow-up.

\section{Inclusion criteria}

Patients aged between 25-85 years with indication of Osteoarthritis, grade I, II, III and IV (Kellgren-Lawrence system) can be from degeneration or chronic injury, patients able to comply with treatment plan, laboratory tests and periodic interviews, patients with adequate renal function (creatinine $\leq 1.5 \mathrm{mg} / \mathrm{dl}$ ), cardiac and respiratory function, blood coagulation activity (PT (INR) $<1.5$, APTT), adequate immune system function, with no known immunodeficiency disease and having greater than 6 months knee pain on the index side (left or right knee) were included in the study.

\section{Exclusion criteria}

Neoplastic cancer within 5 years prior to screening, except for cutaneous basal cell or squamous cell cancer resolved by excision; presence of clinically significant acute or unstable cardiovascular and cerebrovascular (stroke); diagnosis of a transient ischemic attack in the 6 months prior to screening; patients infected with hepatitis B, C or HIV; patients with Body Mass Index (BMI) > $40 \mathrm{~kg} / \mathrm{m} 2$; presence of active infection; and pregnancy \& lactation were excluded from the present study. Any other illness, psychiatric disorder, alcohol or chemical dependence that in the opinion of the investigator would render a patient unsuitable to participate in the study. Conditions/therapies/factors which could confound or interfere with the evaluation of pain/mobility including, but not limited to: knee instability, any varus/valgus deformity of more than $10^{\circ}$, a deformity requiring osteotomy or complex surgery; and gout or pseudo gout. Treatments with strong opioid drugs in the previous 4 weeks for other pain rather than knee osteoarthritis and corticosteroid injection at treatment site within 1 month were excluded. Consistent use of NSAIDs within 48 hours of procedure were not entertained. Health condition (including known allergy to local anaesthetic drug) that did not allow to perform lipo-aspiration in local anaesthesia was excluded.

\section{Patient intake}

Prior to scheduling the patient was screened by the Orthopedician. All inclusion and exclusion criteria were considered and patient intake was done at this time. Images were evaluated.

\section{Study protocol}

\section{Consent}

Risks, benefits and alternatives of treatment were discussed. Patient understands that the proposed therapy was not intended to cure any disease. Patient understands that the intended therapy might have no utility at all and was willing to take the risks of no benefit whatsoever.

\section{Lipo-aspiration (performed by surgeon on staff)}

Patient prepared in a sterile manner. Pre-procedural antibiotics, anxiolytic and/or opioid pain medication administration were done if necessary. Stab incisions were made for cannula entry with \#11 blade after local infiltration with $1 \%$ lidocaine with epinephrine 1:100, 000. Areas to be treated were then infiltrated with the tumescent anaesthesia fluid with the following concentration of lidocaine and epinephrine using the infiltration cannula. ( $40 \mathrm{ml}$ of lidocaine $2 \%$ without epinephrine plus $1 \mathrm{ml}$ of epinephrine $1 \%$ are added to a $1000 \mathrm{ml}$ bag of $0.9 \%$ normal saline). Approximately 300 - 450 cc adipose tissue was aspirated into a sterile container containing sterile $0.9 \%$ normal saline and sodium bicarbonate.

\section{ACRU (autologous adipose tissue cell recovery unit)}

The patient's adipose (fat) that was taken and harvested to lab area and turned to class II Bio Hood "ON". We 
have wiped down surface in hood with $70 \%$ alcohol. Then sample was taken and divided into $50 \mathrm{ml}$ tubes. The fat was processed in ACRU. Ultrasonic cavitation was used to separate fat and stromal vascular fraction. Then $50 \mathrm{ml}$ tubes were centrifuged. A pellet at the bottom of the tube was noticed. We had removed the top layer until we reach $5 \mathrm{ml}$. We did our best not to disturb the pellet. Took a 100-micron filter and screw it onto the $50 \mathrm{ml}$ tube. Turn upside down and use pump to suck it through the filter. Now we have the finished cells, cell and viability count was done in muse cell flow cytometer.

\section{Intra-articular injections}

If the patient had osteoarthritis in both knees then both knees would be injected, with the worst knee identified as the Index knee, which would be reported on. Area was prepared for injection with chlorhexidine. Local anesthetic (lidocaine 1\%) given to skin and deep tissue as needed. SVF was injected ultrasound guided to improve the accuracy of procedure.

\section{Follow up}

Patient was discharged when stable after observation and all post procedure instructions had been discussed. Patient was asked to report any side effects such as fever, pain and others. Patient was seen for follow up next day or within one week. Patients were interviewed by phone, email, or in person and asked to complete the KOOS questionnaires prior to initial treatment, at 1 month, 6 months, 9 months and at 12 months.

\section{Statistical analysis}

Descriptive statistics were used to analyse the capture data at the end of study. Parametric test is used to find the difference in KOOS scores of 58 patients for various subscale, prior to the surgery, one month after the surgery, 6 months, 9 months and 12 months after the surgery. Paired t test was used to find out the difference in pre and post score of patients who underwent SVF therapy, before the treatment, one month after the surgery, 6 months after surgery, 9 months after surgery and 12 months after the treatment. Paired sample t test was used to find the difference between pre score and score after 1, 6, 9 and 12 months of SVF therapy.

\section{RESULTS}

We have given SVF injection to 116 Joints from May 2015 to August 2016. Most of the patients were in age group 51-60 years i.e. 13 out of 58. As per sex distribution there was 37 female and 21 male in study as shown in Figure 1. Majority of the study participants were in the age groups of 51-70 years as in Table 1 . We studied 40 patients 80 joints for 12 Months, 44 patients 88 joints for 09 Months, 55 patients' 110 joints for 06 Months and 58 patients' 116 joints for 01 Month. These all joints were injected with SVF with minimal follow-up of 1 month. We are able to demonstrate safety with no serious side effects reported in 1 month of follow-up and clinical improvement in a vast majority of patients. Some patient's experienced local pain and swelling at the injection site, but those symptoms were lasting shortly and were well controlled with common analgesics.

Table 1: Age group of the patients.

\begin{tabular}{|l|l|l|}
\hline Range & No. of patients & $\%$ \\
\hline $\mathbf{2 5 - 3 0}$ & 1 & 1.72 \\
\hline $\mathbf{3 1 - 3 5}$ & 0 & 0.00 \\
\hline $\mathbf{3 6 - 4 0}$ & 0 & 0.00 \\
\hline $\mathbf{4 1 - 4 5}$ & 1 & 1.72 \\
\hline $\mathbf{4 6 - 5 0}$ & 5 & 8.62 \\
\hline $\mathbf{5 1 - 5 5}$ & 9 & 15.52 \\
\hline $\mathbf{5 6 - 6 0}$ & 13 & 22.41 \\
\hline $\mathbf{6 1 - 6 5}$ & 7 & 12.07 \\
\hline $\mathbf{6 6 - 7 0}$ & 9 & 15.52 \\
\hline $\mathbf{7 1 - 7 5}$ & 7 & 12.07 \\
\hline $\mathbf{7 6 - 8 0}$ & 5 & 8.62 \\
\hline $\mathbf{8 1 - 8 5}$ & 1 & 1.72 \\
\hline Total & 58 & 100.00 \\
\hline
\end{tabular}

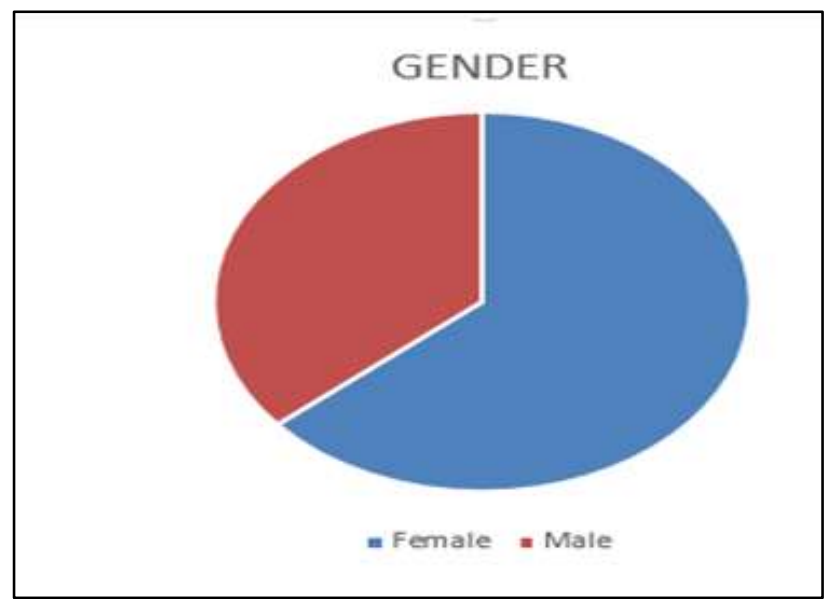

Figure 1: Sex distribution of patients [n=58].

BMI ranges from 17.3 to 51.42 in complete range of patients as given in Figure 2. About 34 patients $(58.6 \%)$ had associated cardiovascular disease, 11 patients (20.69\%) had diabetes Mellitus, 3 patients $(5.17 \%)$ had respiratory disorders, 2 patients $(3.45 \%)$ had neurological disorder and one patient had other endocrine disorder $(1.72 \%)$ but 07 patients $(12.07 \%)$ patients had no associated disease.

Table 2: Grades of osteoarthritis.

\begin{tabular}{|ll|l|}
\hline Grade & F & $\%$ \\
\hline OA $-\mathbf{1}$ & 1 & 1.72 \\
\hline OA -2 & 7 & 12.07 \\
\hline OA -3 & 45 & 77.59 \\
\hline OA -4 & 5 & 8.62 \\
\hline
\end{tabular}


One patient had grade I, 07 patients had grade II, 45 patients had grade III \& 5 patients had grade IV osteoarthritis (as per Kellgren-Lawrence classification) as given in Table 2.

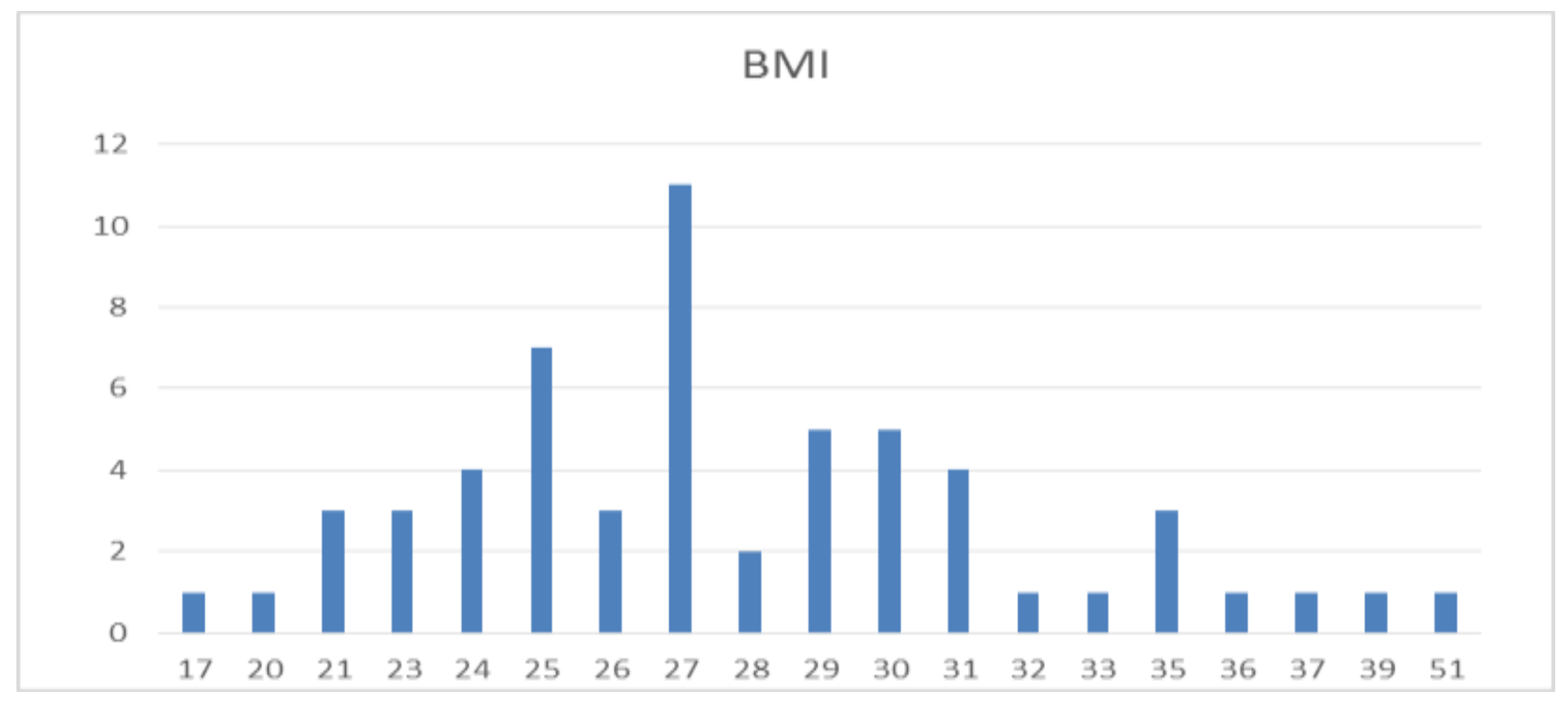

Figure 2: Bar-chart showing BMI of study participants.

Table 3: Paired t test compare the difference in KOOS SCORE pre-operatively \& 1 month postoperatively.

\begin{tabular}{|lllll|}
\hline Pairs & & t & df & Sig. \\
\hline Pair 1 & Pre-op AVG-Post-op AVG 1 month & 9.104 & 57 & 0.000 \\
\hline Pair 2 & Pre-op Pain -Post-op Pain 1 month & 8.128 & 57 & 0.000 \\
\hline Pair 3 & Pre-op Symptom-Post of Symptom 1 month & 1.185 & 57 & 0.2408 \\
\hline Pair 4 & Pre-op AOL-Post -op AOL 1 month & 7.327 & 57 & 0.000 \\
\hline Pair 5 & Pre-op QOL -Post Of QOL 1 month & 8.509 & 57 & 0.000 \\
\hline Pair 6 & Pre-op Sport-Post of Sport 1 month & 3.054 & 57 & 0.003 \\
\hline
\end{tabular}

Table 4: Paired t test compare the difference in KOOS SCORE on $6^{\text {th }}$ month postoperatively.

\begin{tabular}{|lllll|}
\hline Pairs & & t & df & Sig. \\
\hline Pair 1 & Pre-op AVG-Post-op AVG 6 month & 10.67 & 54 & 0.000 \\
\hline Pair 2 & Pre-op Pain -Post-op Pain 6 month & 9.41 & 54 & 0.000 \\
\hline Pair 3 & Pre-op Symptom-Post of Symptom 6 month & 11.39 & 54 & 0.000 \\
\hline Pair 4 & Pre-op AOL-Post -op AOL 6 month & 9.174 & 54 & 0.000 \\
\hline Pair 5 & Pre-op QOL -Post of QOL 6 month & 8.729 & 54 & 0.000 \\
\hline Pair 6 & Pre-op Sport-Post of Sport 6 month & 3.121 & 54 & 0.002 \\
\hline
\end{tabular}

Table 5: Paired $t$ test compare the difference in KOOS SCORE on $9^{\text {th }}$ month postoperatively.

\begin{tabular}{|lllll|}
\hline Pairs & & t & df & Sig. \\
\hline Pair 1 & Pre-op AVG-Post-op AVG 9 month & 14.18 & 43 & 0.000 \\
\hline Pair 2 & Pre-op Pain -Post-op Pain 9 month & 10.19 & 43 & 0.000 \\
\hline Pair 3 & Pre-op Symptom-Post of Symptom 9 month & 9.911 & 43 & 0.000 \\
\hline Pair 4 & Pre-op AOL-Post -op AOL 9 month & 11.75 & 43 & 0.000 \\
\hline Pair 5 & Pre-op QOL -Post of QOL 9 month & 14.2 & 43 & 0.000 \\
\hline Pair 6 & Pre-op Sport-Post of Sport 9 month & 3.744 & 43 & 0.000 \\
\hline
\end{tabular}


Table 6: Paired t test compare the difference in KOOS SCORE on $12^{\text {th }}$ month postoperatively.

\begin{tabular}{|lllll|}
\hline Pairs & & $\mathbf{t}$ & df & Sig. \\
\hline Pair 1 & Pre-op AVG-Post-op AVG 12 month & 15.3 & 39 & 0.000 \\
\hline Pair 2 & Pre-op Pain -Post-op Pain 12 month & 10.96 & 39 & 0.000 \\
\hline Pair 3 & Pre-op Symptom-Post of Symptom 12 month & 10.63 & 39 & 0.000 \\
\hline Pair 4 & Pre-op AOL-Post -op AOL 12 month & 12.39 & 39 & 0.000 \\
\hline Pair 5 & Pre-op QOL -Post of QOL 12 month & 14.94 & 39 & 0.000 \\
\hline Pair 6 & Pre-op Sport-Post of Sport 12 month & 3.957 & 39 & 0.000 \\
\hline
\end{tabular}

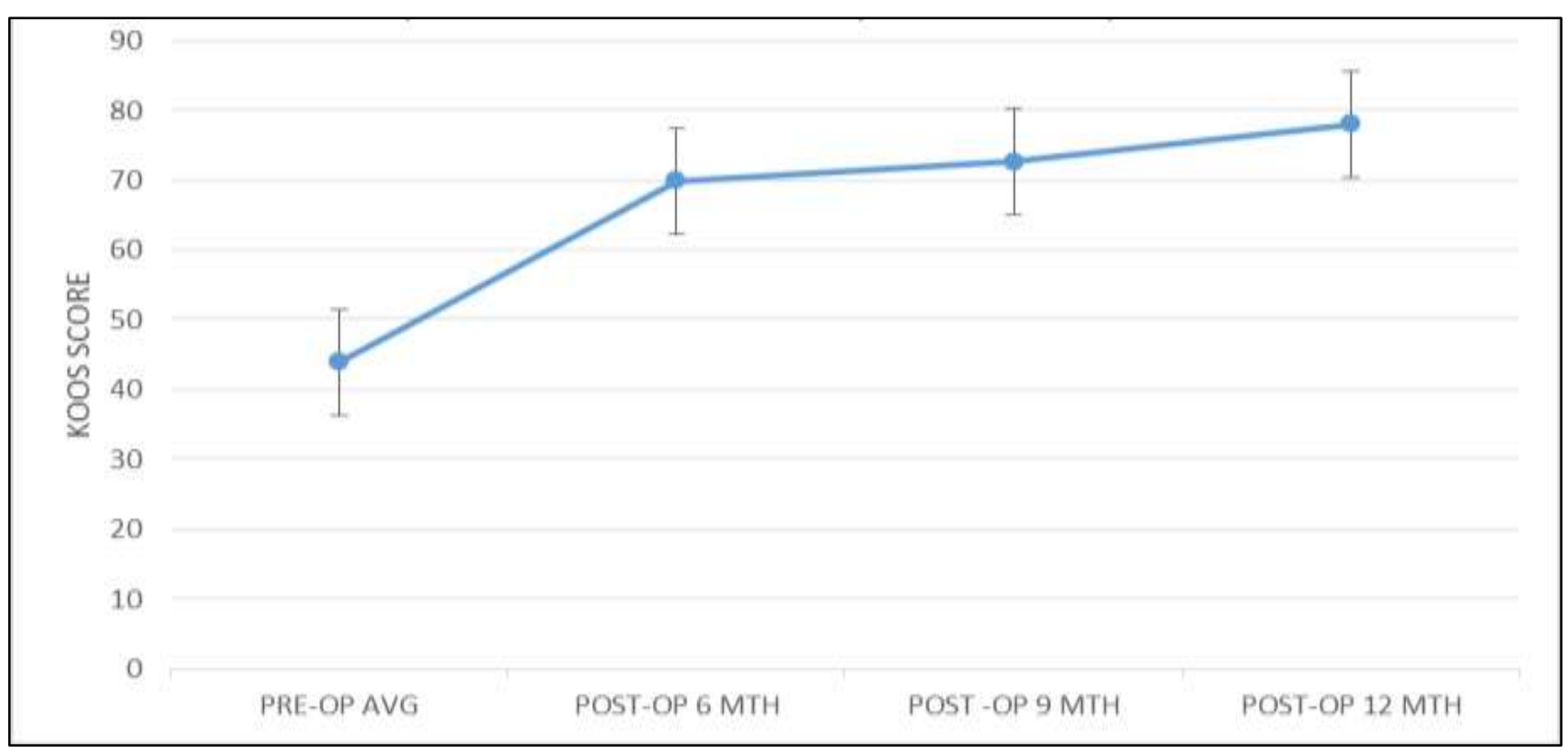

Figure 3: KOOS profiles Pre-Op and Post-Op up to 12 months assessment after autologous grafting of adipose tissue derived SVF done in single surgical sitting $(n=40)$.

At the follow up the difference in the values are statistically significant $(\mathrm{P}<0.05)$ compared with the preoperative status.

Table 7: Comparison of BMI with KOOS score.

\begin{tabular}{|c|c|c|c|c|}
\hline S.No. & Variables & $\mathbf{r}$ & & Sig \\
\hline 1 & \multirow{6}{*}{ BMI } & Post-op AVG 12 months & -0.041 & 0.80 \\
\hline 2 & & Post-op Pain 12 months & -0.102 & 0.52 \\
\hline 3 & & Post-op Symptom 12 months & -0.03 & 0.84 \\
\hline 4 & & Post-op AOL 12 months & -0.09 & 0.57 \\
\hline 5 & & Post-op QoL 12 months & -0.06 & 0.7 \\
\hline 6 & & Post-op Sport 12 months & -0.19 & 0.23 \\
\hline
\end{tabular}

Table 3-6 signifies that $\mathrm{t}$ test shows extremely significant improvement in KOOS score for pain $(\mathrm{t}=8.128)$, symptom $(\mathrm{t}=1.185)$, AoL $(\mathrm{t}=7.327)$, QoL $(\mathrm{t}=8.509)$ and average $(\mathrm{t}=3.054)$ when pre-operative $\& 1$ month scores were compared at the level of $\mathrm{p} \leq 0.05(\mathrm{df}=57)$. A significant improvement as compared to 1 month were seen as for KOOS scores for pain $(t=9.41)$, symptom $(\mathrm{t}=11.39)$, AoL $(\mathrm{t}=9.174)$, QoL $(\mathrm{t}=8.729)$ and average $(\mathrm{t}=3.121)$. When pre-operative \& 6 months scores were compared at the level of $\mathrm{p} \leq 0.05(\mathrm{df}=54)$. A significant improvement in KOOS scores for pain $(\mathrm{t}=10.19)$, symptom ( $\mathrm{t}=9.911)$, AoL $(\mathrm{t}=11.75)$, QoL $(\mathrm{t}=14.2)$ and average $(\mathrm{t}=3.744)$. When pre-operative \& 9 months scores were compared at the level of $\mathrm{p} \leq 0.05(\mathrm{df}=43)$. There is also extremely significant improvement in KOOS scores for pain $(\mathrm{t}=10.96)$, symptom $(\mathrm{t}=10.63)$, AoL $(\mathrm{t}=12.39)$, QoL $(\mathrm{t}=14.94)$ and average $(\mathrm{t}=3.957)$. When pre-operative \& 12 months scores were compared at the level of $\mathrm{p} \leq 0.05(\mathrm{df}=39)$. When scores of 1 month post-op were examined there was no significant difference found in KOOS post-op symptom and post-op pain. But gradually with increase in the follow up months bots the KOOS sub scales improved significantly. Moreover, all clinical results significantly improved at 12 months follow up compared to those at 1 month follow up $(\mathrm{p}<0.05)$. 
A negative correlation was found in BMI and average KOOS $(r=-0.041)$, KOOS pain $(r=-0.102)$, KOOS symptom $(\mathrm{r}=-0.03)$, KOOS AoL $(\mathrm{r}=-0.09)$ and KOOS QoL (-0.06) in patients who underwent autologous grafting of adipose derived stromal vascular fraction in single surgical sitting as in Table 7.

All the patients examined in this study were of various age group ranging from 24 years to 85 years. Also all the grades of osteoarthritis patients were involved in this study to study the effect of adipose derived stromal vascular fraction. The result showed the significant improvement in the joint functions after12 months. The KOOS score changed significantly from pre-op average to post-op average after 12 months. Overall, all the patients reported reduction in the pain, can move normally and carry out their routine living activities. Moreover, all the patients showed no side effects or complication to autologous grafting of adipose derived stromal vascular fraction in single surgical sitting.

\section{DISCUSSION}

All patients underwent treatment with SVF cells as scheduled and no complications related to adipose tissue processing and SVF cells preparations were noticed. There were no serious side effects associated with SVF cell therapy. Other side effects related to the procedure consisted of local pain and swelling at the site of injection, fever, and mild headache.

At this point, we should also clarify the terminology regarding the source of SVF cells. In the vast majority of scientific publications only the term adipose tissue is used, but the true source of SVF cells is not the adipose part but only the stromal (i.e. loose connective tissue) part of the fat obtained typically by liposuction. We can demonstrate indirectly the healing potential of SVF cell therapy in OA using clinical examinations and symptom scoring as well as objective visualization of damaged joints by MRI and X-ray imaging. Since imaging was not the primary aim of this case control study, the follow-up $\mathrm{X}$-ray and/or MRI examination was not performed in all patients. Since it is a short-term follow-up study Thus, we are not able to draw any conclusion on the correlation between clinical improvement and imaging studies.

Knee osteoarthritis is a common chronic orthopaedic disease that significantly reduces the patient's quality of life. This clinical study showed that stromal vascular fraction injection brought about some good results for patients with osteoarthritis. We have seen significant improvement in pain \& symptom score as early as in first month that shows strong anti-inflammatory and analgesic effect of stromal vascular fraction derived from autologous adipose tissue obtained by lipo-aspiration. The anti-inflammatory and pain reduction effects are also contributed by soluble factors secreted from the SVF or ADSCs. ADSCs secrete many important soluble factors, such as HGF, VEGF, NGF, EGF, FGF, and TGF. Unlike
PRP, growth factors from ADSCs are continuously produced after injection of these cells into the joint. ${ }^{27-29}$ Adipose-derived SVF yields a heterogeneous population of cells including stem and progenitor cells with multipotent differentiation potential. SVF cells transcribe many genes that are implicated inflammation, angiogenesis and tissue repair. ${ }^{30}$ It is suggested that adipose derived stromal vascular fraction can have antifibrotic properties by the reduction of local infiltration of inflammatory cells into tissue by the secretion of antifibrotic factors such as interferon- $\gamma$ and matrix metalloproteinases, and by the decrease of profibrotic factors such as transforming growth factor$\beta .^{30,31}$ Advantages of SVF include (1) ease of obtaining cells from lipoaspirates, (2) larger pool of adipose derived mesenchymal cells compared with the pool of bone marrow-derived mesenchymal cells (BM-MC) and (3) stronger angiogenic and regenerative potential of adipose derived mesenchymal cells compared with bone marrow derived mesenchymal cells. ${ }^{32}$

In this study, all patients showed improved joint function after 12 months. The pain score decreased from $8.1 \pm 0.5$ before injection to $4.3 \pm 0.6$ at 6 months, $2.7 \pm 0.5$ at 9 months and $1.5 \pm 0.5$ at 12 months after injection. The KOOSE score increased from $44.3 \pm 11$ before injection to $82 \pm 8.1$ after 12 months of the autologous grafting of adipose derived stromal vascular fraction in a single surgical sitting. Moreover, there were no side effects or complications related to microorganism infection, graft rejection, or tumorigenesis. These results provide a new opportunity for osteoarthritis treatment. ${ }^{22}$ The patients will be further monitored and longer follow-up data will help to answer question about durability and long-term safety of adipose derived stromal vascular fraction. Although in a clinical study, with autologous grafting of stromal vascular fraction in a single surgical sitting almost all patients showed significant improvement in all clinical outcomes at the final follow-up examination. All clinical results significantly improved at 12-months follow-up compared to initial examination before the treatment $(\mathrm{P}<0.05)$. Moreover, none of the patients underwent total knee arthroplasty during this 12 months period. $^{24}$ Another limitation of our study is no randomization and no placebo control.

There were two reasons for designing that case control study: 1) ethical aspect and 2) economical aspect. We believe it would be rather unethical to ask placebo group of patients to undergo lipoaspiration and placebo administration to the joint with OA. Since this study was designed as autologous grafting of adipose derived stromal vascular fraction in a single surgical sitting, there is strong previously documented clinical evidence of safety of autologous non-manipulated or minimally manipulated cell therapies. ${ }^{33}$ On the other hand, this study is well designed and strong evidence for minimal risks based on previous studies exists, can lead to a costeffective, safe, ethical and objective evaluation of a novel treatment. $^{34}$ 


\section{CONCLUSION}

To summarize, autologous grafting of adipose derived stromal vascular fraction done in a single surgical sitting is a safe and efficient method for treating osteoarthritis. The efficiency of grafting clearly improved after 6,9 and 12 months. Overall, $100 \%$ of patients were satisfied with this method. Pain was sturdily reduced after therapy, and the quality of life was significantly improved. Although further studies with control subjects and more patients need to be performed to confirm the above results, this study suggests that autologous grafting of adipose derived stromal vascular fraction done in a single surgical sitting is a promising minimally invasive therapy for osteoarthritis patients.

\section{Funding: No funding sources}

Conflict of interest: None declared

Ethical approval: The study was approved by the institutional ethics committee

\section{REFERENCES}

1. Woolf AD, Pfleger B. Burden of major musculoskeletal conditions. Bulletin WHO. 2003;81(9):646-56.

2. Silman AJ, Hochberg MC. Epidemiology of the rheumatic diseases. Oxford: Oxford University Press; 1993.

3. Murray CJL, Lopez AD, editors. The global burden of disease. A comprehensive assessment of mortality and disability from diseases, injuries, and risk factors in 1990 and projected to 2020. Cambridge (MA): Harvard School of Public Health on behalf of the World Health Organization and The World Bank; 1996.

4. Chronic rheumatic conditions. World Health Organization. Available at http://www.who.int/chp/topics/rheumatic/en/.

Accessed on 16 November, 2016]

5. Barbour KE, Helmick CG, Theis KA, Murphy LB, Hootman JM, Brady TJ, et al. Prevalence of doctordiagnosed arthritis and arthritis-attributable activity limitation-United States, 2010-2012. MMWR. 2013;62(44):869-73.

6. Mahajan A, Verma S, Tandon V. Osteoarthritis. J Assoc Physicians India. 2005;53:634-41.

7. Shiel Jr WC. Osteoarthritis (OA or Degenerative Arthritis). Available at: http://www.medicinenet.com/osteoarthritis/article.ht m. Accessed on 02 December, 2016.

8. Lassen MR, Ageno W, Borris LC, Lieberman JR, Rosencher N, Bandel TJ, et al. Rivaroxaban versus enoxaparin for thromboprophylaxis after total knee arthroplasty. N Engl J Med. 2008;358:2776-86.

9. Parry MC, Smith AJ, Blom AW. Early death following primary total knee arthroplasty. J Bone Joint Surg Am. 2011;93:948-53.

10. Schrama JC, Espehaug B, Hallan G, Engesaeter LB, Furnes O, Havelin LI, et al. Risk of revision for infection in primary total hip and knee arthroplasty in patients with rheumatoid arthritis compared with osteoarthritis: a prospective, populationbased study on 108,786 hip and knee joint arthroplasties from the Norwegian Arthroplasty Register. Arthritis Care Res. 2010;62:473-9.

11. Thorey F, Reck F, Windhagen H. Influence of bone density on total hip resurfacing arthroplasty in patients with osteonecrosis of the femoral head - a radiological analysis. Technol Health Care. 2008;16:151-8.

12. Hafezi Nejad N, Guermazi A, Roemer FW, Eng J, Zikria B, Demehri S. Reply to the letter: Long term use of analgesics and risk of osteoarthritis progressions and knee replacement. Osteoarthritis Cartilage. 2016;24(4):597-604.

13. Hollenberg $\mathrm{CH}$, Vost A. Regulation of DNA synthesis in fat cells and stromal elements from rat adipose tissue. J Clin Invest. 1969;47:2485-98.

14. Hematti P, Keating A. Mesenchymal stromal cells in regenerative medicine: A Perspective. In: Hematti P, Keating A, editors. Mesenchymal Stromal Cells. Biology and clinical applications. New York, NY: Humana Press; 2013: 3-16.

15. Black LL, Gaynor J, Gahring D, Adams C, Aron D, Harman $S$, et al. Effect of adipose-derived mesenchymal stem and regenerative cells on lameness in dogs with chronic osteoarthritis of the coxofemoral joints: a randomized, double-blinded, multicenter, controlled trial. Vet Ther. 2007;8:27284.

16. Koga H, Shimaya M, Muneta T, Nimura A, Morito $\mathrm{T}$, Hayashi $\mathrm{M}$, et al. Local adherent technique for transplanting mesenchymal stem cells as a potential treatment of cartilage defect. Arthritis Res Ther. 2008;10:84.

17. Sato M, Uchida K, Nakajima $H$, Miyazaki $T$, Guerrero AR, Watanabe $\mathrm{S}$, et al. Direct transplantation of mesenchymal stem cells into the knee joints of Hartley strain guinea pigs with spontaneous osteoarthritis. Arthritis Res Ther. 2012;14:31.

18. Strioga M, Viswanathan S, Darinskas A, Slaby O, Michalek J. Same or not the same? Comparison of adipose tissue-derived versus bone marrow-derived mesenchymal stem and stromal cells. Stem Cells Dev. 2012;21:2724-52.

19. Centeno CJ, Schultz JR, Cheever M, Freeman M, Faulkner S, Robinson B, et al. Safety and complications reporting update on the reimplantation of culture expanded mesenchymal stem cells using autologous platelet lysate technique. Curr Stem Cell Res Ther. 2011;6:368-78.

20. Michalek J, Moster R, Lukac L, Proefrock K, Petrasovic M, Rybar J, et al. Autologous adipose tissue-derived stromal vascular fraction cells application in patients with osteoarthritis. Cell Transplant. 2015; doi: 10.3727/096368915X686760. 
21. Mizuno H, Tobita M, Uysal AC. Concise review: Adipose-derived stem cells as a novel tool for future regenerative medicine. Stem Cells. 2012;30:804-10.

22. Yoshimura K, Suga H, Eto H. Adipose-derived stem/progenitor cells: roles in adipose tissue remodeling and potential use for soft tissue augmentation. Regen Med. 2009;4:265-73.

23. Bui KH, Duong TD, Nguyen TN, Nguyen TD, Le VT, Mai VT, et al. Symptomatic knee osteoarthritis treatment using autologous adipose derived stem cells and platelet-rich plasma: a clinical study. Biomed Res Ther. 2014;1:2-8.

24. Gimble JM, Guilak F, Bunnell BA. Clinical and preclinical translation of cell/based therapies using adipose tissue/derived cells. Stem Cell Res Ther. 2010;1:19.

25. Koh YG, Choi YJ, Kwon SK, Kim YS, Yeo JE. Clinical results and second-look arthroscopic findings after treatment with adipose-derived stem cells for knee osteoarthritis. Knee Surg Sports Traumatol Arthrosc. 2013.

26. Vangsness CT, Farr J, Boyd J, Dellaero DT, Mills CR, LeRoux-Williams M. Adult human mesenchymal stem cells delivered via intra-articular injection to the knee following partial medial meniscectomy: a randomized, double-blind, controlled study. J Bone Joint Surg Am. 2014;96:90-8.

27. Roos EM, Stefan Lahmander L. The Knee injury and Osteoarthritis Outcome Score (KOOS): from joint injury to osteoarthritis. Health Qual Life Outcomes. 2003;1:64.

28. Kilroy GE, Foster SJ, Wu X, Ruiz J, Sherwood S, Heifetz A, et al. (2007). Cytokine profile of human adipose-derived stem cells: expression of angiogenic, hematopoietic, and pro-inflammatory factors. J Cellular Physiol. 2007;212:702-9.
29. Salgado AJ, Reis RL, Sousa NJ, Gimble JM. Adipose tissue derived stem cells secretome: soluble factors and their roles in regenerative medicine. Current Stem Cell Research \& Ther. 2010;5:103-10.

30. Van Pham P, Bui KH, Ngo DQ, Vu NB, Truong $\mathrm{NH}$, Phan NL, et al. Activated platelet-rich plasma improves adipose-derived stem cell transplantation efficiency in injured articular cartilage. Stem Cell Research \& Ther. 2013;4:91.

31. Katz AJ, Tholpady A, Tholpady SS, Shang H, Ogle RC. Cell surface and transcriptional characterization of human adipose-derived adherent stromal (hADAS) cells. Stem Cells. 2005;23(3):412-23.

32. Lee SH, Lee EJ, Lee SY, Kim JH, Shim JJ, Shin C, et al. The effect of adipose stem cell therapy on pulmonary fibrosis induced by repetitive intratracheal bleomycin in mice. Exp Lung Res. 2014;40(3):117-25.

33. Ikegame $\mathrm{Y}$, Yamashita $\mathrm{K}$, Hayashi S, Mizuno $\mathrm{H}$, Tawada M, You F, et al. Comparison of mesenchymal stem cells from adipose tissue and bone marrow for ischemic stroke therapy. Cytotherapy. 2011; 13(6):675-85.

34. Mason C, Manzotti E. Regenerative medicine cell therapies: numbers of units manufactured and patients treated between 1988 and 2010. Regen Med. 2010;5:307-313.

Cite this article as: Tantuway V, Bhambani $\mathrm{P}$, Nagla A, Mantry P, Sharma S, Mehto P, et al. Autologous grafting of non manupulated freshly isolated - adipose tissue derived stromal vascular fraction in single surgical sitting for treatment of knee osteoarthritis. Int J Res Orthop 2017;3:107-15. 